A C G

publications

Org. Commun. 14:1 (2021) 58-72

organic

communications

\title{
Exploring the in-silico approach for assessing the potential of natural compounds as a SARS-CoV-2 main protease inhibitors
}

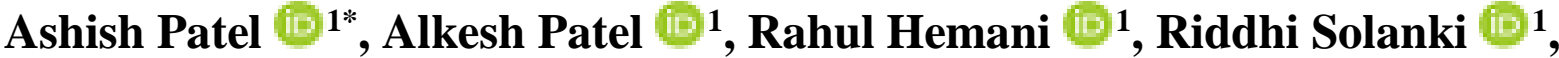 \\ Janki Kansara $\oplus^{1}$, Gargi Patel $\oplus^{1}$, Sayantan Pradhan $\oplus^{2}$ \\ and Tushar Bambharoliya ${ }^{3}$
}

\author{
${ }^{1}$ Ramanbhai Patel College of Pharmacy, Charotar University of Science and Technology, Changa, Ta. \\ Petlad, Dist. Anand, Gujarat, India \\ ${ }^{2}$ Department of Chemistry, Jadavpur University, Jadavpur, Kolkata, India \\ ${ }^{3}$ North Carolina State University, North Carolina, USA
}

(Received December 07, 2020; Revised March 25, 2021; Accepted March 01, 2021)

\begin{abstract}
The SARS-CoV-2 virus emerged as a major cause of the COVID-19 pandemic in December 2019. Many attempts have been made to block the viral infection by targeting various processes like its entry, uncoating, replication, activating $\mathrm{T}$ cells response, and rising antibody titer. Also, many drugs are repurposed like remdesivir, dexamethasone, tocilizumab, hydroxychloroquine based on their established therapeutic efficacy against other viruses in the past. Natural products (NP) consist of a promising candidate and are needed to evaluate those molecules with molecular docking for preliminary screening and in vitro studies. Therefore, in the present study, a total of 12 active constituents from natural products like Ashwagandha, Tinospora cordifolia, Tea, Neem and lemon balm were docked, using the Autodock tool, onto the crystal structure of SARS CoV-2 main protease (PDB ID-5R80), to study their capability to act as main protease (Mpro) COVID-19 inhibitors. All NPs derivatives displayed good binding energies $(\Delta \mathrm{G})$ ranging from -8.8 to $-5.2 \mathrm{kcal} / \mathrm{mol}$, but berberine, epicatechin, and rosmarinic acid were found most potent, among others. Therefore, good binding energy, druglikeness, and efficient pharmacokinetics suggest the potential of NPs derivatives as SARS-CoV-2 main protease (Mpro) inhibitors. However, further research is necessary to investigate the ability of these compounds as COVID-19 inhibitors.
\end{abstract}

Keywords: SARS-CoV-2; main protease; natural products; molecular docking; viral infection; drug-likeness. (C2021 ACG Publication. All right reserved.

\section{Introduction}

Coronaviruses envelop Positive-sense single-stranded RNA viruses that belong to the Coronaviridae family. They normally affect birds and rodents and cause minor respiratory illnesses. ${ }^{1}$ However, these viruses have caused lethal endemic diseases in the recent past, such as Extreme Acute Respiratory Syndrome (SARS) and endemic Middle East Respiratory Syndrome (MERS). ${ }^{1}$ Wuhan city in China became the focus of a surge in cases of pneumonia due to an unexplained cause in December 2019. In January 2020, a novel coronavirus called SARS-CoV-2 was isolated from these patients with pneumonia, ${ }^{2}$ and the disease was referred to by the World Health Organization in February 2020 as Coronavirus disease 2019 (COVID-19). ${ }^{3,4}$ While the outbreak may have begun with the zoonotic transmission in the seafood market, wild animals were also sold, it became obvious that the disease was transmitted from person to person ${ }^{5}$. This disease's clinical features are common, consisting of asymptomatic infections, mild respiratory illness, extreme respiratory failure, pneumonia, and even death. ${ }^{6-8}$ The COVID-19 pandemic presents a major challenge to global public health, ${ }^{9}$ calling on its causative agent, the SARS-CoV-2 virus, to develop safe and effective prophylactics and

\footnotetext{
* Corresponding author: E-Mail: aashishpate12388@gmail.com
} 
therapies against infection. ${ }^{10-11}$ Although many drugs like remdesivir, dexamethasone, tocilizumab, and hydroxychloroquine have been repurposed based on their immunomodulatory and pro-inflammatory cytokines (IL-6, TNF- $\alpha$ ) inhibitory activities, there is need to develop safe and efficacious medicines which will work in all category of the human population.

Azadirachtin is a triterpenoid class limonoid found in the Juss trees of Azadirachta indica A. Besides, treatment with Azadirachta indica A juss in mice exposed to cigarette smoke-and lipopolysaccharide-induced pulmonary inflammation has shown that inflammatory cell infiltration and free radical development have decreased significantly. Besides, the amount of pro-inflammatory cytokines decreases significantly in the lungs, such as tumour necrosis factor-aa (TNF-a), interleukin (IL)-6, along with a decrease in the expression of synthase of inducible nitric oxide (iNOS), which is thought to be the key factors behind pulmonary inflammation. An extracellular signal-regulated kinase (ERK) and c-Jun N-terminal kinase (JNK) signalling pathway attenuations have also been reported with inhibition of the phosphorylation of the nuclear factor

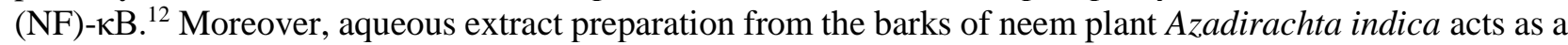
potent entry inhibitor against $\mathrm{HSV}-1$ infection into natural target cells. At concentrations ranging from 50 to $100 \mu \mathrm{g} / \mathrm{mL}$, the Neem bark extract (NBE) significantly blocked HSV-1 entry into cells. When the extract was pre-incubated with the virus but not with the target cells, the blocking activity of NBE was observed, indicating a clear anti-HSV-1 property of the neem bark. Furthermore, NBE-treated virions failed to bind the cells, suggesting an NBE function as an attachment stage blocker. HSV-1 glycoprotein-mediated cell-to-cell fusion and polykaryocyte formation were also inhibited by cells treated with NBE, indicating an additional role for NBE at the stage of viral fusion. ${ }^{13}$

Besides, nimbolide, an active phytochemical agent of Azadirachta indica, prevents HSV-1 from entering cells at 50 to $100 \mu \mathrm{g} / \mathrm{mL}^{14}$ Virucidal activity against coxsackievirus virus B-4 at 50 to $100 \mu \mathrm{g} / \mathrm{mL}$ has also been shown. ${ }^{15}$ In addition, camphor has a range of biological properties, including insecticidal, antimicrobial, antiviral, anticoccidial, anti-nociceptive, anticancer, and antitussive. The essential oil of the aerial components of Artemisia апnиа consists of $44 \%$ camphor. ${ }^{16}$ The biological characteristics of camphor are antiviral, insecticidal, antimicrobial, anti-nociceptive, anticancer, and antitussive. Camphor was shown to have an IC50 value of $0.88 \mu \mathrm{g} / \mathrm{mL}$ and $0.7 \mu \mathrm{g} / \mathrm{mL}$ for HSV-1 and HSV-2, respectively, in the plaque reduction assay, indicating inhibition of cell-to-cell transmission of both viruses. ${ }^{17}$ Camphor displayed herpes simplex virus-1 virucidal activity followed by cytotoxic activity against cells of the African Green Monkey kidney (Vero). The essential oil of lavender cotton (Santolina insularis), rich in camphor, deactivated in vitro herpes simplex type 1 ( HSV-1) and typed 2 (HSV-2) using plaque reduction assays with an IC50 value of $0.88 \mu \mathrm{g} / \mathrm{mL}$ for HSV-1 and $0.7 \mu \mathrm{g} / \mathrm{mL}$ for HSV-2. ${ }^{18}$

Besides this, through direct targeting and blocking its replication cell culture, epicatechin from green tea has demonstrated virucidal activity against the influenza virus. The antiviral effects are often due to the interaction of hemagglutinin and neuraminidase with a change in the viral membrane's physical property. ${ }^{19}$ Epicatechin has demonstrated reverse transcriptase inhibition in HIV-1 under in vitro conditions ${ }^{20}$ Regular consumption of beverages containing catechins shows efficacy in preventing the upper respiratory tract's acute infections. ${ }^{21}$ Epicatechin demonstrated potent antiviral activity in bioassays that protected the cells from almost all viral infection effects. ${ }^{22}$

Berberine, an isoquinoline alkaloid, also decreases the virus's replication and the unique interactions between the virus and its host. Berberine prevents the synthesis of DNA and intercalates itself into DNA by reversing transcriptase activity. There is evidence available to block replication by berberine of human immunodeficiency virus, human papillomavirus, herpes simplex virus, and human cytomegalovirus. Berberine modulates many vital pathways involved in viral replication like the AMP-activated protein kinase/mammalian target of rapamycin (AMPK/mTOR), mitogen-activated protein kinase/ extracellular

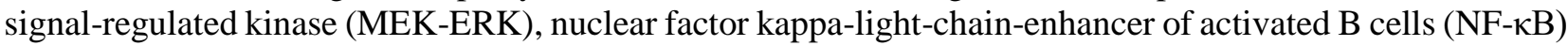
and supports the host antiviral immune response. ${ }^{23}$ Berberine has shown anti-inflammatory properties by regulating the level of pro-inflammatory cytokines like IL-13, IFN- $\gamma$, IL-6, TNF- $\alpha$, and prevent inflammatory cell infiltration process through the inhibition of NF- $\mathrm{KB}$ and activation of AMP-activated protein kinase. ${ }^{24}$

However, several pro-inflammatory cytokines in the pathophysiological processes involved in chronic respiratory diseases are affected by the anti-inflammatory properties of berberine that function through several pathways such as the NFfB, ERK1/2, and p38 MAPK pathways. Mice treated with berberine showed it decreased Myeloperoxidase activity and decreased the number of neutrophils in bronchoalveolar lavage fluid (BALF). ${ }^{25}$ Berberine displayed in vivo and in vitro antiviral effects of $0.05,0.025,0.0125$, $0.00625,0.003125,0.001563 \mathrm{~g} / \mathrm{L}$ concentrations on influenza viruses in the MDCK cell line. ${ }^{26}$ 
Exploring the potential of natural compounds as a SARS-CoV-2 protease inhibitors

Moreover, palmatine is a berberine alkaloid, and an organic heterotetracyclic compound play role as a plant metabolite. The anti-SARS-CoV-2 main protease complex (Mpro) was seen in the mouse model at a bodyweight of $135 \mathrm{mg} / \mathrm{kg} .{ }^{27}$ Palmatine prevents Zika virus infection by blocking A549 and BHK-21 cells' virus binding, entry, and stability at 10 to $80 \mathrm{mM} \cdot{ }^{28}$ Palmatine demonstrated inhibitory activity against NS2BNS3 protease activity at $96 \mu \mathrm{M} .{ }^{29}$ Luteolin is an anti-inflammatory flavonoid ${ }^{30}$ and a cytokine modulator ${ }^{31}$ believed to affect alveolar macrophage activity and peripheral macrophage activity.

In the experimental respiratory allergy model, rosmarinic acid potentiates carnosic acid-induced apoptosis in lung fibroblasts ${ }^{32}$ and decreases eosinophilic airway inflammation. ${ }^{33}$ Virucidal effects against enterovirus infection have been demonstrated in vitro and in vivo. ${ }^{34}$ Rosmarinic acid has shown its antiviral and anti-inflammatory impact in the experimental murine model of Japanese Encephalitis. ${ }^{35}$ Inhibition of viral proteases required for the proteolytic treatment of polyproteins, however, has been a promising strategy for demonstrating the ability of protease inhibitors to treat viral infections in the pharmacological treatment of human immunodeficiency viruses HIV and hepatitis C, respectively. Similarly, the main protease of SARS-CoV-2 is considered necessary for viral replication and is considered a promising goal for antiviral pharmacotherapy. The crystal structure of the main protease SARS-CoV-2 has recently been solved, allowing specific inhibitory compounds' rational design. The computational molecular docking and in silico ADMET approach to the discovery of major inhibitors of SARS-CoV-2 protease is thus illustrated in our study. ${ }^{36}$

\section{Experimental}

\subsection{Molecular Docking Study}

To obtain binding modes and binding affinities of natural products(NPs), molecular docking was used. In silico drug design, the binding mode of NPs and affinity to SARS-CoV-2 main protease is essential. ${ }^{37}$ The protein structure of SARS-COV-2 was obtained from the protein data bank (PDB id: 5R80). Autodock Tools has modified the protein (SARS-COV-2) and ligand (NPs) structures. The SARS-COV-2 chain is altered by removing water and a bound ligand. Missing amino acids have been checked, and the protein structure has been added with hydrogen. Center Grid box x: 10.0885, y:-1.47267, z:-21.9779, and the number of points in the dimensions $\mathrm{x}, \mathrm{y}, \mathrm{z}$ are respectively considered to be $30 \times 30 \times 30 \AA 3$, and the grid spacing is $0.3750 \AA$ A. By adding Gasteiger charges, detecting root, and choosing torsions from the Autodock Tools panel's torsion tree, Ligands were prepared..$^{38}$ The docking procedure was carried out using the Lamarckian genetic algorithm. Docking of natural products on windows platforms with 8 GB RAM and Intel I 5 processor was carried out with AutoDock 4.2.6. ${ }^{39}$

\subsection{Preparation of Active Site}

The target for an enzyme's inhibition is the active site. However, the active protease site was predicted by the online server MetaPocket 2.0 (https://projects.biotec.tu-dresden.de/metapocket/). Moreover, the processed protein data bank's file without heteroatoms was uploaded, and the top result was selected for docking from the best three possible ligand-binding sites (based on the $\mathrm{z}$-score). Table 1 indicates the protease active site that was used in the study. The predicted amino acid residues were then compared with the amino acids in the Mpro co-crystallized complex with Z18197050 at the active site. Molecular docking was only effective after this stage.

\subsection{Molecular Docking Validation by Decoy Ligand}

The docking protocol was validated using the decoy ligand method in which DUD-E online servers (http://dude.docking.org/) obtained decoy ligands identical to Z18197050 and docked them against the active Mpro site. Decoys are compounds that are identical in physical properties that might not bind effectively to a protein concerning the reference ligand. It was done to increase the ligand's enrichment, which is necessary for assessing the docking process and removing false positives. These were conducted to verify the docking process to ensure docking validation. 


\subsection{In-silico Drug-likeness and Pharmacokinetic Property Prediction}

Using pkCSM online prediction platforms, in-silico prediction studies were conducted to test the ligands' theoretical pharmacokinetics to predict the drug-likeness of the ligands. ${ }^{40}$ The program determined pharmaceutically related characteristics such as H-bond donor, $\mathrm{H}$-bond acceptor, octanol-water partition coefficient $(\log P)$, surface area, and the number of rotatable bonds. In addition to the effect of ligands on ADME parameters such as water solubility, Caco2 permeability, human intestinal absorption, skin permeability, inhibition of P-glycoprotein I and II, the volume of distribution, unbound drug fraction, bloodbrain barrier and CNS permeability, inhibition of cytochrome P450 (inhibition of CYP3A4 and CYP2C9), total clearance, renal OCT2 (organic cation transportation) and on toxicity parameters like AMES toxicity, hERG I and II inhibition, oral rat acute toxicity, oral rat chronic toxicity, hepatotoxicity, skin sensitization, the toxicity of pyriformis and minnows, cytotoxicity and measurement of the overall recommended tolerated dose.

Table 1. The active site of Mpro predicted using MetaPocket 2.0

\begin{tabular}{|c|c|c|}
\hline No & Amino Acid & Residue Number \\
\hline 1 & Threonine & 24 \\
\hline 2 & Threonine & 25 \\
\hline 3 & Threonine & 26 \\
\hline 4 & Leucine & 27 \\
\hline 5 & Histidine & 41 \\
\hline 6 & Valine & 42 \\
\hline 7 & Cysteine & 44 \\
\hline 8 & Threonine & 45 \\
\hline 9 & Serine & 46 \\
\hline 10 & Glutamic acid & 47 \\
\hline 11 & Aspartic acid & 48 \\
\hline 12 & Methionine & 49 \\
\hline 13 & Leucine & 50 \\
\hline 14 & Asparagine & 51 \\
\hline 15 & Proline & 52 \\
\hline 16 & Tyrosine & 54 \\
\hline 17 & Tyrosine & 118 \\
\hline 18 & Asparagine & 119 \\
\hline 19 & Phenylalanine & 140 \\
\hline 20 & Leucine & 141 \\
\hline 21 & Asparagine & 142 \\
\hline 22 & Glycine & 143 \\
\hline 23 & Serine & 144 \\
\hline 24 & Cysteine & 145 \\
\hline 25 & Histidine & 163 \\
\hline 26 & Histidine & 164 \\
\hline 27 & Methionine & 165 \\
\hline 28 & Glutamic acid & 166 \\
\hline 29 & Leucine & 167 \\
\hline 30 & Proline & 168 \\
\hline 31 & Histidine & 172 \\
\hline 32 & Aspartic acid & 187 \\
\hline 33 & Arginine & 188 \\
\hline 34 & Glutamine & 189 \\
\hline 35 & Threonine & 190 \\
\hline 36 & Alanine & 191 \\
\hline 37 & Glutamine & 192 \\
\hline 38 & Alanine & 193 \\
\hline
\end{tabular}




\section{Results and Discussion}

\subsection{Molecular Docking Studies}

The PDB file of the Crystal Structure of SARS-CoV-2 main protease in complex with Z18197050 (5R80) was downloaded from the PDB databank. These structures were used to predict the binding of NPs and their derivatives (Figure.1) to the main protease of SARS CoV-2. Moreover, Table 1 gives the binding energies of all active constituents of natural products and their derivatives with 5R80 (binding energies ranged from -8.8 to $-5.2 \mathrm{kcal} / \mathrm{mol}$ ). In addition to, visual examination of the computationally docked optimal binding poses of all NPs on main 3Cl- protease $\left(\mathrm{M}_{\text {pro }}\right.$ ) of COVID-19 revealed the important role of various types of interactions viz. hydrogen bonding and hydrophobic interactions, including $\pi-\pi$ stacking, $\pi-$ cation, and $\pi-\sigma$ interactions in the stability of NPs.

Among the twelve compounds, berberine, epicatechin, and rosamarinic acid have shown the best docking score against SARS-COV-2 main protease. The docking score of all other NPs is given in Table 2. Berberine and epicatechin are bound efficiently to the active site of SARS-COV-2 main protease with good complementarity, and the docking score is -8.8 and $-8.1 \mathrm{kcal} / \mathrm{mol}$, respectively (Table 2 ). Moreover, berberine has formed six hydrogen bonding with the active site of SARS CoV-2 main protease amino acid-like HIS 41, GLU 166, LEU 167, ARG 188, ASP 187, and one hydrophobic interaction with MET 165 (Figure 2), while epicatechin has formed five hydrogen bonding with PHE 140, SER 144, HIS 164, GLU 166, ARG 188 and two hydrophobic interaction with HIS 41 and MET 49 (Figure 3). However, identifying the ligandbinding site (composed of amino acids) for each specific protein molecule is crucially important when trying to find a suitable drug molecule for the target. It is also essential to understand the function of the protein. These binding interactions (Figure 2,3) present a clear view that berberine and epicatechin can irreversibly interact with SARS-COV-2 main protease. Bond distance and binding interaction of berberine and epicatechin with an active amino acid of SARS CoV-2 main protease are outlined in Table 3 and Table 4

Table 2. Molecular docking results of NPs with SARS-CoV-2 main protease (5R80).

\begin{tabular}{llcccc}
\hline No & $\begin{array}{c}\text { Natural } \\
\text { products }\end{array}$ & $\begin{array}{c}\text { Docking score } \\
\text { (kcal/mol) }\end{array}$ & $\begin{array}{c}\text { Ligand } \\
\text { Efficiency }\end{array}$ & $\begin{array}{c}\text { Intermolecular } \\
\text { energy }\end{array}$ & $\begin{array}{c}\text { XP } \\
\text { H-Bond }\end{array}$ \\
\hline 1 & Azadirachtin & -6.2 & $\mathbf{- 0 . 1 6}$ & $\mathbf{- 7 . 2 5}$ & $\mathbf{- 8 . 4 5 3 2}$ \\
$\mathbf{2}$ & Berberin & $\mathbf{- 8 . 8}$ & $\mathbf{- 0 . 1 2}$ & $\mathbf{- 6 . 5 6}$ & $\mathbf{- 4 . 5 8 1 5}$ \\
3 & Camphor & -5.4 & -0.31 & -6.44 & -7.1426 \\
$\mathbf{4}$ & Epicatechin & $\mathbf{- 8 . 1}$ & $\mathbf{- 0 . 1 4}$ & $\mathbf{- 9 . 1 8}$ & $\mathbf{- 1 3 . 4 5 6 6}$ \\
5 & Luteolin-5- & -7.5 & -0.21 & -4.04 & 0 \\
& glucoside & & & & \\
6 & Nigellicimine & -5.8 & -0.46 & -6.19 & -7.4677 \\
7 & Nigellidine & -6.5 & -0.22 & -5.62 & -10.4768 \\
8 & Nimbolide & -6.9 & -0.13 & -6.87 & -17.1579 \\
$\mathbf{9}$ & Palmitine & $-\mathbf{7 . 3}$ & $\mathbf{- 0 . 2 4}$ & $-\mathbf{- 6 . 3 3}$ & $-\mathbf{9 . 5 6 6 1}$ \\
10 & p-Cymene & -5.2 & -0.41 & -6.30 & -10.1061 \\
$\mathbf{1 1}$ & Rosmarinic & $\mathbf{- 7 . 9}$ & $\mathbf{- 0 . 2 1}$ & $\mathbf{- 7 . 2 2}$ & $\mathbf{- 9 . 6 8 4 2}$ \\
& acid & & & & -7.5778 \\
12 & Tembeterine & -6.9 & -0.14 & -6.74 & \\
\hline
\end{tabular}




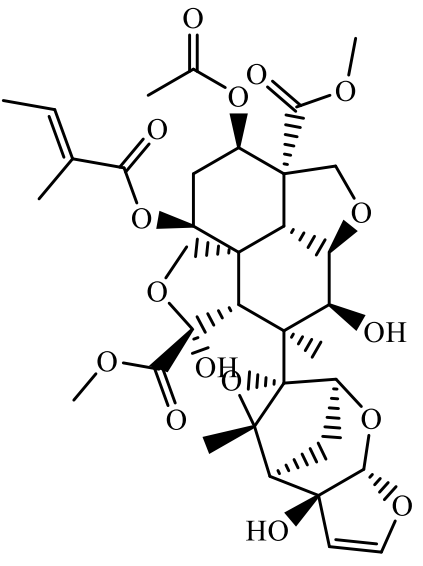

Azadirachtin<smiles>COc1ccc2cc3[n+](cc2c1OC)CCc1cc2c(cc1-3)OCO2</smiles>

Berberine

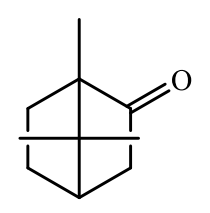<smiles>Cc1ccc(C(C)C)cc1</smiles>

Camphor

p-cymene<smiles>Oc1cc(O)c2c(c1)O[C@H](c1ccc(O)c(O)c1)[C@H](O)C2</smiles>

Epicatechin<smiles>O=C(/C=C/c1ccc(O)c(O)c1)OC(Cc1ccc(O)c(O)c1)C(=O)O</smiles>

Rosmarinic acid<smiles>O=c1cc(-c2ccc(O)c(O)c2)oc2cc(O[C@@H]3O[C@H](CO)[C@@H](O)[C@H](O)[C@H]3O)cc(O)c12</smiles>

Luteolin-5-Glucoside

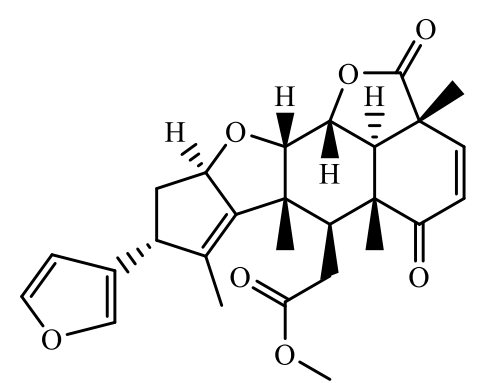

Nimbolide<smiles>COc1cc2c(cc1OC)-c1cc3ccc(O)c(OC)c3c[n+]1CC2</smiles>

Palmitine<smiles>Cc1cc(O)c2c([O-])[n+]3n(c2c1)CCCC3</smiles>

Nigellidine<smiles>COc1ccc(C[C@H]2c3cc(O)c(OC)cc3CC[N+]2(C)C)cc1O</smiles>

Tembeterine

Figure 1. Structure of selected active constituents of natural products that displayed a high binding affinity for SARS-CoV-2 


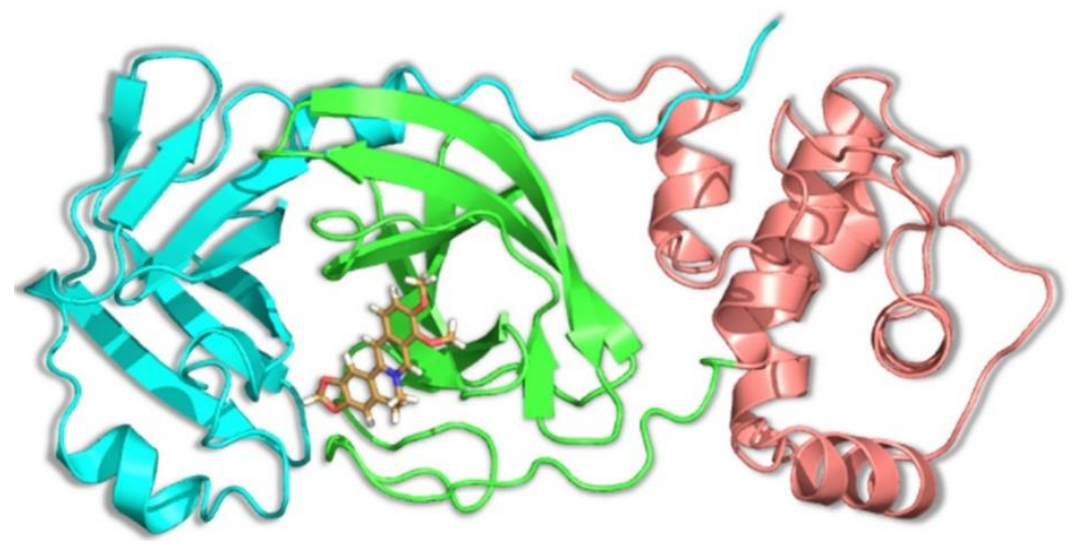

(a)

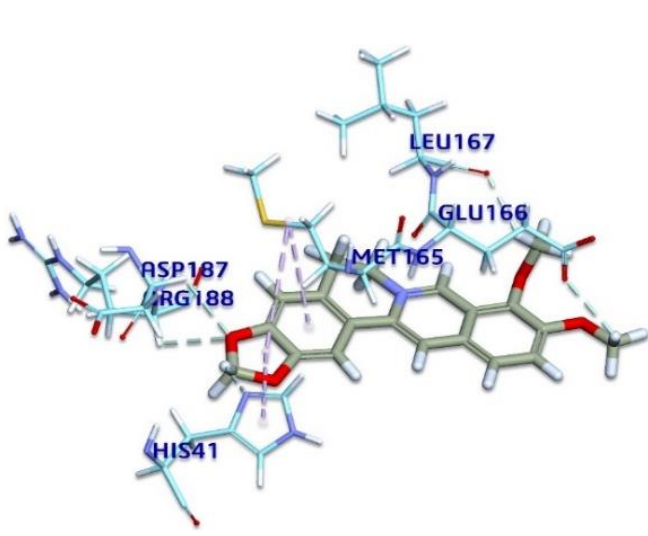

(b)

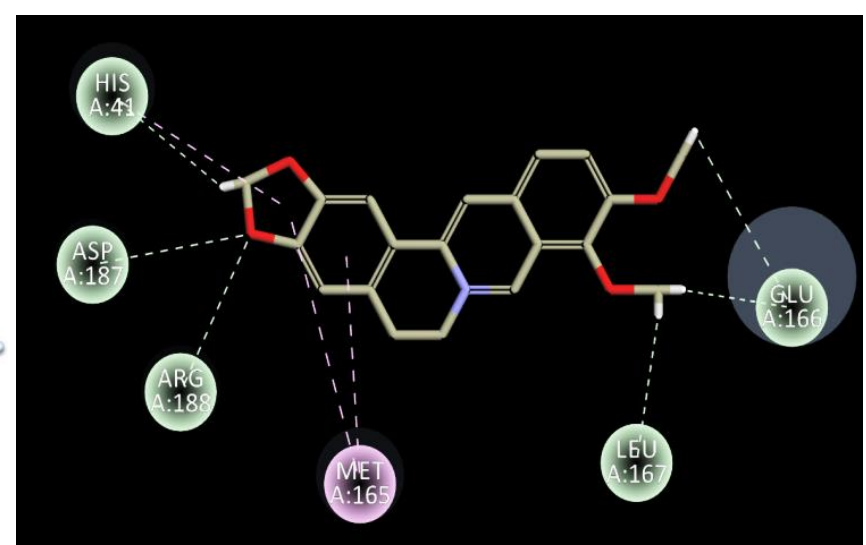

(c)

Figure 2. Comprehensive perception of SARS-COV-2 main protease and Berberin through molecular docking

(a) Secondary structure of SARS-COV-2 main protease represented by ribbon and Berberin represented is by stick model (b) 3D representation of binding interactions of Berberin with SARS-COV-2 main protease amino acids (Bonds are in dots, and NPS (brown) surrounding amino acids (sky blue) are in three letters code).

(c) 2D representation of the binding interactions of berberine with SARS-COV-2 main protease.

Table 3. Bond distances and Binding Interaction of Berberin with SARS-COV-2 main protease

\begin{tabular}{lccc}
\hline \multicolumn{1}{c}{$\begin{array}{c}\text { Molecule Name } \\
\text { Berberine }\end{array}$} & $\begin{array}{c}\text { Distance } \\
(\mathbf{\AA})\end{array}$ & Bond category & Bond type \\
\hline Berberine:H43 - A:LEU167:O & 2.43327 & Hydrogen Bond & Carbon Hydrogen Bond \\
Berberine:H32 - A:HIS41: ND1 & 2.65242 & Hydrogen Bond & Carbon Hydrogen Bond \\
Berberine:H42 - A:GLU166:OE1 & 2.76916 & Hydrogen Bond & Carbon Hydrogen Bond \\
Berberine:H39 - A:GLU166:OE1 & 2.90919 & Hydrogen Bond & Carbon Hydrogen Bond \\
Berberine:O11 - A:ARG188:HA & 3.03168 & Hydrogen Bond & Carbon Hydrogen Bond \\
Berberine:O11 - A:ASP187:HA & 3.04867 & Hydrogen Bond & Carbon Hydrogen Bond \\
Berberine- A: MET165 & 4.49349 & Hydrophobic & Pi-Alkyl \\
\hline
\end{tabular}




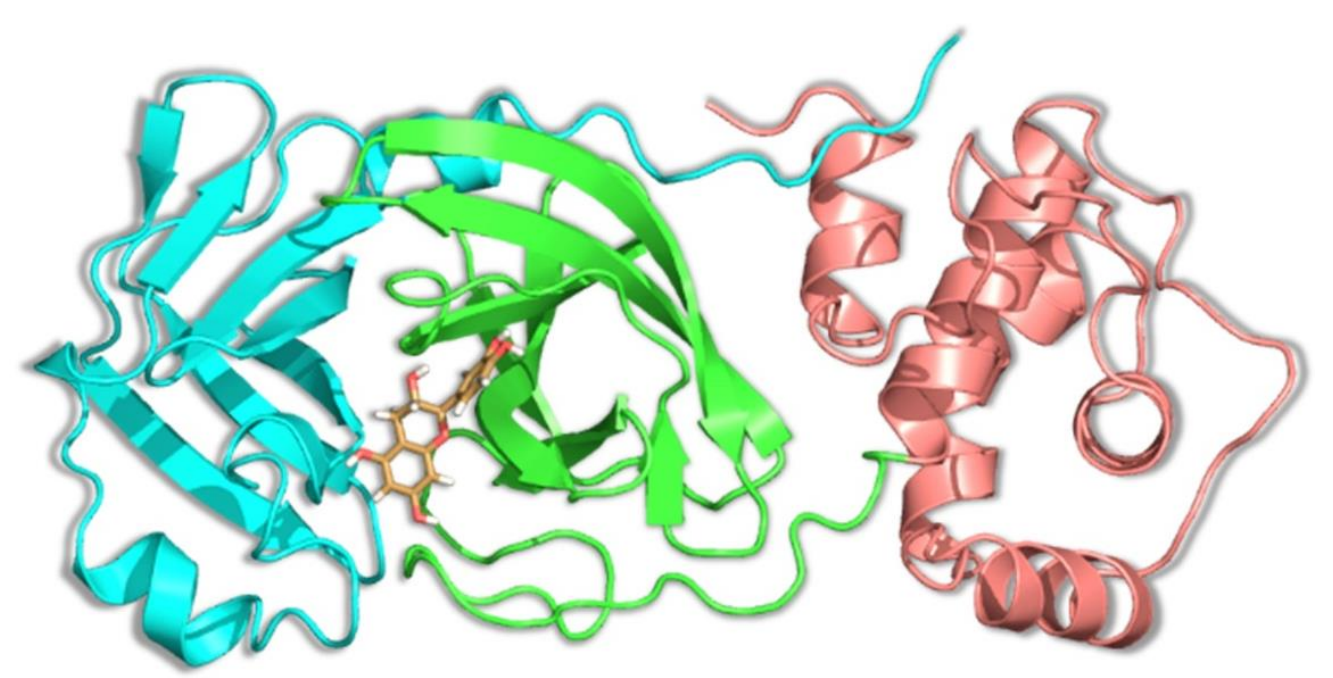

(a)

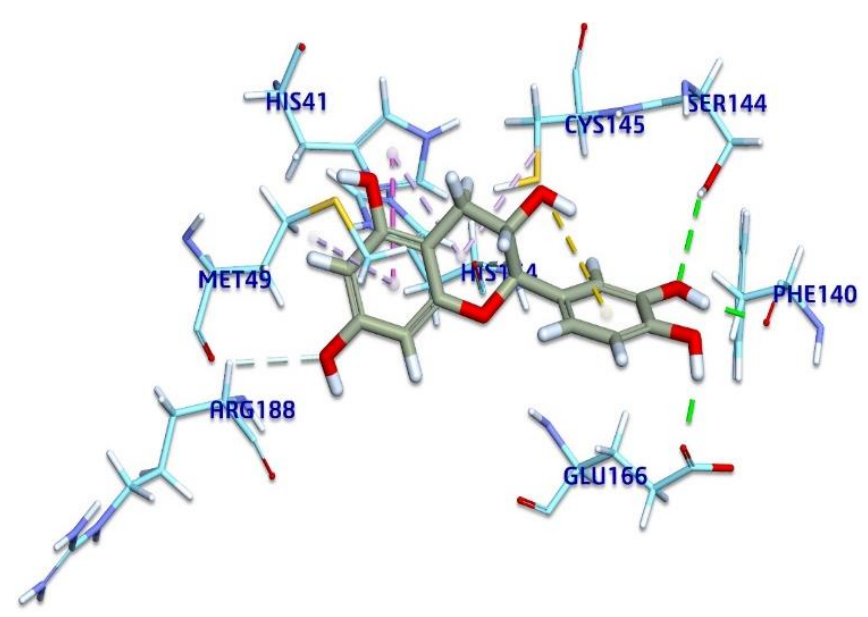

(b)

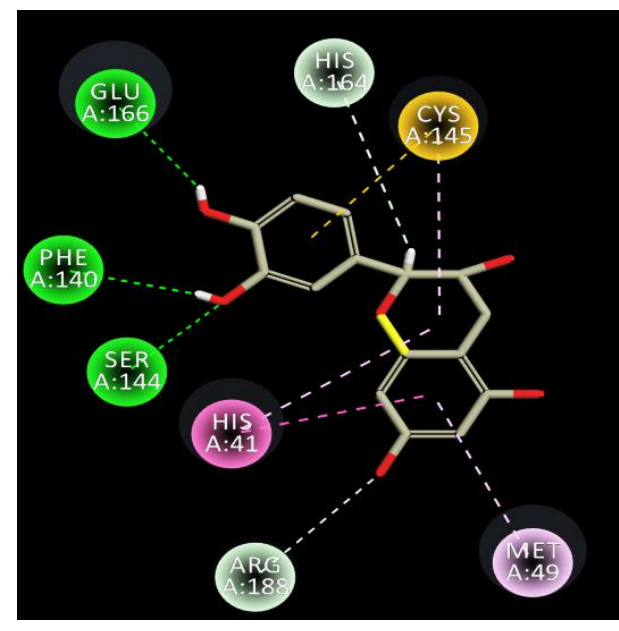

(c)

Figure 3. Comprehensive perception of SARS-COV-2 main protease and epicatechin through molecular docking,

(a) secondary structure of SARS-COV-2 main protease represented by ribbon and epicatechin represented is by stick model (b) 3D representation of binding interactions of Epicatechin with SARS-COV-2 main protease amino acids. (Bonds are in dots. NPS (brown) surrounding amino acids (sky blue) are in three letters code). (c) $2 \mathrm{D}$ representation of the binding interactions of Epicatechin with SARS-COV-2 main protease

Table 4. Bond distances and Binding Interaction of Epicatechin with SARS-COV-2 main protease

\begin{tabular}{lccc}
\hline \multicolumn{1}{c}{$\begin{array}{c}\text { Molecule Name } \\
\text { Epicatechin }\end{array}$} & $\begin{array}{c}\text { Distance } \\
(\AA)\end{array}$ & Bond category & Bond type \\
\hline Epicatechin: H32 -A: PHE140:O & 1.94258 & Hydrogen Bond & Conventional Hydrogen Bond \\
Epicatechin: H31 -A:GLU166: OE1 & 1.97462 & Hydrogen Bond & Conventional Hydrogen Bond \\
Epicatechin: H25- A: HIS164:O & 2.71174 & Hydrogen Bond & Carbon Hydrogen Bond \\
Epicatechin: O8-A:SER144: HG & 2.76147 & Hydrogen Bond & Conventional Hydrogen Bond \\
Epicatechin: O14-A:ARG188: HA & 2.87064 & Hydrogen Bond & Carbon Hydrogen Bond \\
Epicatechin - A: HIS41 & 4.29547 & Hydrophobic & Pi-Pi Stacked \\
Epicatechin - A: MET49 & 4.86094 & Hydrophobic & Pi-Alkyl \\
Epicatechin - A:CYS145: SG & 5.19251 & Other & Pi-Sulfur \\
\hline
\end{tabular}




\subsection{Validation of Molecular Docking by Decoy Ligands}

Decoy ligands are believed not to bind to the target molecule because the chemical properties affect the interactions between a ligand and a target and a simple technique for evaluating the AutoDock 4.2.6 software protocol and performance. However, compared to Z18197050-Mpro, re-docked complex to prove the docking efficiency, docking a ligand to a target must display high binding energy. A total of 51 decoy ligands similar to Z18197050 were retrieved from the DUD-E web server. Binding energies are reported in Table S1. Their binding energies remained between -8.42 to $-3.12 \mathrm{kcal} / \mathrm{mol}$ (Table S1, see supporting information). However, compared to the re-docked complex, only one Decoy Ligand had low binding energy and ranked higher. It has been found that only a negligible amount of decoy has greater binding affinity than the re-docked complex, thus confirming the efficiency and protocol of docking.

\subsection{In-silico Drug-likeness and Pharmacokinetic Property Prediction}

Based on Lipinski's law, all structures used for docking were analyzed for in silico drug-likeness using the pkCSM server (Table 5). For all the compounds, the expected lipophilicity (expressed as LogP) was found to be well over the conventional cut-off value of 5 used for drug design. Reasonable MW values (MW < 500) necessary for effective penetration through biological membranes are shown in natural products and their derivatives used in this analysis. For all substances, the surface area (SA) was found to be 62.89$292.77 \AA^{2}$ range, which is well within the limit. All compounds fall into the acceptable range, suggesting the candidate molecule's strong bioavailability. For all compounds except Luteolin-5-glucoside, the number of hydrogen bond acceptors (HBA, $\leq 10)$ and donors $(\mathrm{HBD}, \leq 5)$ was in accordance with Lipinski's rule of five.

Table 5. In-silico prediction of drug-likeness for some active natural compounds ${ }^{\text {[a] }}$

\begin{tabular}{lccccccc}
\hline Compound & MW & LogP & SA & HBA & HBD & $\mathbf{n}_{\text {violations }}$ & $\begin{array}{c}\text { Rotatable } \\
\text { bonds }\end{array}$ \\
\hline Azadirachtin & 720.72 & -0.20 & 292.77 & 10 & 3 & 0 & 6 \\
Berberine & 336.36 & 3.06 & 144.86 & 4 & 0 & 0 & 2 \\
Camphor & 152.23 & 2.40 & 68.17 & 1 & 0 & 0 & 0 \\
Epicatechin & 290.27 & 1.54 & 119.66 & 6 & 5 & 0 & 1 \\
Luteolin-5- & 448.38 & -0.24 & 179.10 & 11 & 7 & 2 & 4 \\
glucoside & & & & & & & \\
Nigecillimine & 203.24 & 2.56 & 88.65 & 3 & 0 & 0 & 2 \\
Nigellidine & 218.25 & 0.81 & 93.33 & 3 & 1 & 0 & 0 \\
Nimbolide & 466.53 & 3.74 & 198.03 & 7 & 0 & 0 & 3 \\
Palmitine & 369.41 & 3.20 & 157.71 & 5 & 0 & 0 & 4 \\
$\begin{array}{l}\text {-cymene } \\
\text { Rosmarinic }\end{array}$ & 134.22 & 3.11 & 62.89 & 0 & 0 & 0 & 1 \\
acid & 360.31 & 1.76 & 147.39 & 7 & 5 & 0 & 6 \\
Tembeterine & 344.43 & 3.03 & 148.18 & 4 & 2 & 0 & 4 \\
\hline
\end{tabular}

[a] MW = Molecular weight, $\log \mathrm{P}=$ octanol-water partition coefficient, $\mathrm{SA}=$ Surface Area, HBA = Number of hydrogen bond acceptor, $\mathrm{HBD}=$ Number of hydrogen bond donor, $\mathrm{n}_{\text {violations }}=$ violations from Lipinski's rule.

Additionally, various key ADMET (Absorption, Distribution, Metabolism, Excretion, and Toxicity) properties have also been calculated with the pkCSM server's aid. The results are listed in Table 6 and Table 7. All NPs derivatives showed moderate to high water solubility ranging from $-1.55 \mathrm{log} \mathrm{mol} / \mathrm{L}$ (Nigellidine) to $-4.37 \mathrm{log} \mathrm{mol} / \mathrm{L}$ (Nimbolide). In addition to high Caco-2 permeability (permeation > 0.90) except compound Rosmarinic acid (permeation= 0.07 ) which showed less permeability. Intestinal absorption (IA) is greater than $85 \%$, indicating good permeation across the intestinal membrane except for Rosmarinic acid. 
67 Exploring the potential of natural compounds as a SARS-CoV-2 protease inhibitors

Table 6. In-silico ADME prediction for some active natural compounds ${ }^{\text {[a] }}$

\begin{tabular}{lcccccccccccccc}
\hline \multicolumn{1}{c}{ Compound } & \multicolumn{9}{c}{ Absorption } & \multicolumn{4}{c}{ Distribution } & \multicolumn{4}{c}{ Metabolism } & \multicolumn{2}{c}{ Excretion } \\
& WS & CP & IA & SP & PI-1 & PI-2 & VD & FU & BBB & CNS & CI-1 & CI-2 & TC & RS \\
\hline Azadirachtin & -3.05 & 0.92 & 100 & -2.73 & No & No & 0.92 & 0.27 & -1.85 & -2.97 & Yes & Yes & 0.12 & No \\
Berberine & -3.87 & 0.99 & 98.89 & -2.73 & No & No & 0.7 & 0.27 & -0.60 & -1.62 & Yes & Yes & 1.28 & No \\
Camphor & -2.86 & 1.50 & 96.88 & -2.74 & No & No & 0.33 & 0.45 & -0.62 & -2.17 & No & No & 0.10 & No \\
Epicatechin & -3.39 & 0.91 & 93.20 & -2.73 & No & No & 0.40 & 0.05 & -1.09 & -2.30 & Yes & Yes & 0.32 & No \\
Luteolin-5- & -2.97 & 1.12 & 85.36 & -2.73 & No & No & 0.02 & 0.06 & -1.78 & -4.59 & Yes & Yes & 0.57 & No \\
glucoside & -2.90 & 1.43 & 98.68 & -2.81 & No & No & -0.07 & 0.28 & -0.11 & -2.38 & Yes & Yes & 0.67 & No \\
Nigecillimine & -1.55 & 1.17 & 93.92 & -2.79 & No & No & 0.71 & 0.61 & -0.19 & -2.80 & Yes & Yes & 0.90 & No \\
Nigellidine & -4.37 & 0.97 & 100 & -3.06 & No & No & 0.26 & 0.09 & -0.06 & -2.78 & Yes & Yes & 0.25 & No \\
Nimbolide & -3.73 & 1.28 & 99.83 & -2.73 & No & No & 0.68 & 0.27 & -0.71 & -2.31 & Yes & Yes & 1.45 & No \\
Palmitine & -4.02 & 1.34 & 95.52 & -2.74 & No & No & 0.53 & 0.26 & 0.54 & -3.34 & Yes & Yes & 0.23 & No \\
p-cymene & -3.32 & 0.07 & 45.22 & -2.73 & No & No & 0.03 & 0.18 & -1.54 & -3.54 & No & Yes & 0.33 & No \\
Rosmarinic acid & -3.13 & 1.29 & 94.93 & -3.00 & No & No & 1.42 & 0.31 & -0.17 & -2.26 & Yes & Yes & 1.13 & No \\
Tembeterine & $-W$
\end{tabular}

[a] Abbreviations: WS - Water solubility (log mol/L), CP - Caco2 permeability (log Papp in 10-6 cm/s), IA - Human intestinal absorption (\% Absorbed), SP - Skin permeability (log Kp), PI-1 - P-glycoprotein I inhibitor, PI-2 - P-glycoprotein II inhibitor, VD - Human volume of distribution (log L/kg), FU - Fraction unbound (human) (Fu), BBB - BBB permeability (logBB), CNS - CNS permeability (log PS), CI-1 - CYP3A4 inhibitor, CI-2 - CYP2C9 inhibitor, TC - Total clearance (log mL/min/kg), RS - Renal OCT2 (organic cation transporter 2) substrate. Azad: Azadirachtin, Berb: Berberine, Camp: Camphor, Epica: Epicatechin, Lute: Luteolin-5-glucoside, Nigec: Nigecillimine, Nigel: Nigellidine, Nimbo: Nimbolide, Palm: Palmitine, p-cyme: pcymene, Rosma: Rosmarinic acid, Tembe: Tembeterine 
Further, all NPs showed good permeation through the skin (permeation > -2.5). Additionally, all NPs showed no inhibition towards P-glycoprotein I and P-glycoprotein II. Furthermore, all NPs showed poor BBB permeability and moderate CNS permeability except Rosmarinic acid and p-cymene. All showed inhibition towards the metabolizing enzyme CYP3A4 except Camphor and Rosmarinic acid, while except camphor, all showed inhibition towards CYP2C9. All NPs derivatives were found to show the total clearance in the range of $0.10 \log \mathrm{mL} / \mathrm{min} / \mathrm{kg}$ (Camphor) to $1.45 \mathrm{log} \mathrm{mL} / \mathrm{min} / \mathrm{kg}$ (Palmitine). Further, all NPs derivatives were found to act as OCT2 substrate, indicating that these compounds will not have any adverse interactions and no negative effect on renal clearance.

Table 7. In-silico ADME prediction for some active natural compounds ${ }^{[a]}$

\begin{tabular}{lcccccccccc}
\hline \multicolumn{1}{c}{ Compound } & AT & MRTD & hERGI & hERGII & ORAT & ORCT & HT & SS & TPT & MT \\
\hline Azadirachtin & No & -0.28 & No & No & 2.852 & 4.002 & No & No & 0.285 & 8.469 \\
$\begin{array}{l}\text { Berberine } \\
\text { Luteolin-5- }\end{array}$ & No & 0.197 & No & No & 3.015 & 1.142 & No & No & 0.289 & -0.78 \\
glucoside & 0.658 & No & Yes & 2.566 & 3.854 & No & No & 0.285 & 1.879 \\
Camphor & No & 0.614 & No & No & 1.714 & 1.981 & No & Yes & 0.267 & 1.34 \\
Epicatechin & Yes & 0.694 & No & No & 1.787 & 3.08 & No & No & 0.337 & 1.839 \\
Nigellicimine & No & 1.019 & No & No & 2.535 & 2.173 & No & No & 0.713 & 1.123 \\
Nigellidine & No & -0.314 & No & No & 2.616 & 0.73 & Yes & No & 0.502 & 1.818 \\
Palmitine & No & 0.203 & No & Yes & 2.916 & 1.129 & No & No & 0.291 & -0.731 \\
$\begin{array}{l}p \text {-cymene } \\
\text { Rosmarinic }\end{array}$ & No & 0.96 & No & No & 1.592 & 2.404 & No & Yes & 0.822 & 0.61 \\
acid & 0.698 & No & No & 2.495 & 3.893 & No & No & 0.285 & 2.396
\end{tabular}

[a] AT - AMES toxicity, MRTD- maximum recommended tolerated dose (human, log mg/kg/day), hERGIhERG I inhibitor, hERGII - hERG II inhibitor, ORAT-oral rat acute toxicity (LD50, mol/kg), ORCT-oral rat chronic toxicity (lowest dose of a compound that results in an observed adverse effect (LOAEL), log mg/ kg_bw/day), HT- hepatotoxicity, SS- skin sensitization, TPT-T. Pyriformis toxicity (log $\mu \mathrm{g} / \mathrm{L}$ ), MT-minnow toxicity $(\log \mathrm{mM})$.

\section{Conclusion}

The outbreak of SARS-CoV-2 around the world and the effects are an impressive reminder of the danger to public health and the economy of zoonotic diseases in many countries due to the lack of specific therapeutics against the novel virus, encouraging the development of new drug compounds for which computational methods provide a quick and cost-effective solution.

After the emergence of a global pandemic situation, many researchers searched for effective prophylactic and therapeutic strategies against COVID-19 by using in silico, in vitro, and in vivo. Based on the molecular docking analysis conducted by Anuj Kumar et al., three compounds, i.e., ursolic acid, carvacrol, and oleanolic acid, were potential inhibitors Mpro, fulfilling Lipinski's rule of five and ADME parameters with the stability of all three docking complexes at $50 \mathrm{~ns} .{ }^{41}$ Screening of several natural compounds by docking analysis conducted by Rohan R. Narkhede et. suggests that compounds like glycyrrhizin, tryptanthrine, rhein, and berberine may inhibit COVID-19 Mpro because of their higher degree of interaction with protease. ${ }^{42}$ Rutin, isorhamnetin-3-O-b-D, and calendoflaside, which are flavonoids found in Calendula officinalis, possess higher binding affinity towards Mpro. Molecular dynamics simulation(100ns) study of these compounds revealed their stability and flexibility towards Mpro. ${ }^{43}$

Molecular docking study conducted by Siti Khaerunnisa et al. found that medicinal plant compounds like kaempferol, quercetin, luteolin-7-glucoside, demethoxycurcumin, naringenin, apigenin-7-glucoside, oleuropein, curcumin, catechin, and epicatechin-gallate may inhibit COVID-19 Mpro. ${ }^{44}$ Amaresh Mishra et. used Lopinavir and Ritonavir as standard reference drugs due to their known protease inhibitory activity 
against HIV for in-silico analysis of various medicinal compounds. Based on the binding energy to viral protease, Amentoflavone and Guggulsterone showed the lowest binding energy. ${ }^{45}$ Adem et al. found that in comparison with nelfinavir, the binding affinity of hesperidin and rutin was better on molecular docking to Mpro of Covid-19 and these compounds also possess a biologically safe profile. ${ }^{46}$

The different herbal compounds found effective against COVID-19 through preventing hyper inflammation and cytokines storm-like conditions. ${ }^{47}$ By inhibiting the development of pro-inflammatory virus-induced cytokines, such as IL-6, IL-8, and TNF-alpha, Echinacea shown anti-inflammatory impact. It can be studied that cytokine production is impaired after administering echinacea to a group of virus-infected cells ${ }^{48}$ Curcumin is a natural polyphenolic compound from roots of rhizome Curcuma longa used extensively in Indian traditional herbal medicines exerts antiviral activities against many viruses like Zikavirus, Adenovirus, HIV, Influenza virus, and Hepatitis virus. ${ }^{49}$ Curcumin has lowered the pro-inflammatory effects of the angiotensin II-AT1R axis-induced COVID-19, leading to a decrease in the amount of proinflammatory cytokines and free radicals ${ }^{50}$ and has demonstrated efficacy in preventive measures to stop the spread of SARS-COV2 infection to humans.${ }^{51} \beta$-Escins are mixtures of Japanese horse chestnut saponin has shown activities against SARS-CoV (EC50 of $6.0 \mu \mathrm{M})$ anti-antiviral effects by the inhibition of NF- $\kappa \mathrm{B}$ and activator protein-1 signaling pathways along with reducing the levels of TNF-alpha and IL-6. ${ }^{52-54}$

Using the molecular docking approach via the auto dock tool, we calibrated the best molecules which bind to specific target more efficiently and provide the desired efficacy. Moreover, In-silico drug-likeness and pharmacokinetic property prediction using pkCSM online prediction platforms revealed that all bestscored compounds had drug-like characteristics for potential use as COVID-19 inhibitors. However, experimental validation and subsequent optimization of our proposed naturally active compounds might offer a valuable strategy and could be explored as protease inhibitors to conquer SARS-CoV-2. Vaccine production, availability, and accessibility for all populations (pediatric, geriatric, pregnant women, and patients suffering from immunocompromised disorders) is a big challenge. So, we need prophylactic and therapeutic supports from NP.

It can be concluded that out of a total of 12 compounds, the best docking score against SARSCOV-2 main protease has been shown by berberine, epicatechin, and rosmarinic acid.

\section{Acknowledgements}

We thank the Student Startup Innovation Policy (SSIP) Cell, Govt of Gujarat, India, for providing financial support for research work under the SOIC scheme (SOIC2021_002113) and Ramanbhai Patel College of Pharmacy, Charotar University of Science and Technology, Gujarat, for their support in carrying out this work.

\section{Supporting Information}

Supporting information accompanies this paper on http://www.acgpubs.org/journal/organiccommunications

\section{ORCID}

Ashish Patel: $\underline{0000-0001-5773-3756}$

Alkesh Patel: $\underline{0000-0001-7036-5011}$

Rahul Hemani: 0000-0002-9039-3498

Riddhi Solanki: 0000-0001-5623-2212

Janki Kansara: 0000-0002-1747-1576

Gargi Patel: 0000-0003-3414-2085

Sayantan Pradhan: 0000-0003-4884-7772

Tushar Bambhroliya: 0000-0002-1056-2432 
Exploring the potential of natural compounds as a SARS-CoV-2 protease inhibitors

\section{References}

[1] Kahn, J.; McIntosh, K. History and recent advances in coronavirus discovery. Pediatr. Infect. Dis J. 2005, 24, S223-S227.

[2] Gorbalenya, A.; Baker, S.; Baric, R.; de Groot, R.; Drosten, C.; Gulyaeva, A.; Haagmans, B.; Lauber, C.; Leontovich, A.; Neuman, B.; Penzar, D.; Perlman, S.; Poon, L.; Samborskiy, D.; Sidorov, I.; Sola, I.; Ziebuhr, J. The species severe acute respiratory syndrome-related coronavirus: classifying 2019-Ncov and naming it SARS-Cov-2. Nat. Microbiol. 2020, 5, 536-544.

[3] Jiang, S.; Shi, Z.; Shu, Y.; Song, J.; Gao, G.; Tan, W.; Guo, D. A Distinct name is needed for the new coronavirus. Lancet. 2020, 395, 949-950.

[4] https://www.who.int/docs/default-source/coronaviruse/situation-reports/20200316-sitrep-56-covid-19.pdf (accessed Aug 20, 2020).

[5] Li, Q.; Guan, X.; Wu, P.; Wang, X.; Zhou, L.; Tong, Y.; Ren, R.; Leung, K.; Lau, E.; Wong, J.; Xing, X.; Xiang, N.; Wu, Y.; Li, C.; Chen, Q.; Li, D.; Liu, T.; Zhao, J.; Liu, M.; Tu, W.; Chen, C.; Jin, L.; Yang, R.; Wang, Q.; Zhou, S.; Wang, R.; Liu, H.; Luo, Y.; Liu, Y.; Shao, G.; Li, H.; Tao, Z.; Yang, Y.; Deng, Z.; Liu, B.; Ma, Z.; Zhang, Y.; Shi, G.; Lam, T.; Wu, J.; Gao, G.; Cowling, B.; Yang, B.; Leung, G.; Feng, Z. Early transmission dynamics in wuhan, china, of novel coronavirus-infected pneumonia. New Engl. J. Med. 2020, 382, 1199-1207.

[6] Chen, W.; Vermaak, I.; Viljoen, A. Camphor-A fumigant during the black death and a coveted fragrant wood in ancient egypt and babylon-A review. Molecules, 2013, 18, 5434-5454.

[7] Huang, C.; Wang, Y.; Li, X.; Ren, L.; Zhao, J.; Hu, Y.; Zhang, L.; Fan, G.; Xu, J.; Gu, X.; Cheng, Z.; Yu, T.; Xia, J.; Wei, Y.; Wu, W.; Xie, X.; Yin, W.; Li, H.; Liu, M.; Xiao, Y.; Gao, H.; Guo, L.; Xie, J.; Wang, G.; Jiang, R.; Gao, Z.; Jin, Q.; Wang, J.; Cao, B. Clinical features of patients infected with 2019 novel coronavirus in Wuhan, China. Lancet. 2020, 395, 497-506.

[8] Chen, N.; Zhou, M.; Dong, X.; Qu, J.; Gong, F.; Han, Y.; Qiu, Y.; Wang, J.; Liu, Y.; Wei, Y.; Xia, J.; Yu, T.; Zhang, X.; Zhang, L. Epidemiological and clinical characteristics of 99 cases of 2019 novel coronavirus pneumonia in Wuhan, China: A descriptive study. Lancet. 2020, 395, 507-513.

[9] Wang, D.; Hu, B.; Hu, C.; Zhu, F.; Liu, X.; Zhang, J.; Wang, B.; Xiang, H.; Cheng, Z.; Xiong, Y.; Zhao, Y.; Li, Y.; Wang, X.; Peng, Z. Clinical characteristics of 138 hospitalized patients with 2019 novel coronavirusinfected pneumonia in Wuhan, China. JAMA-J. Am. Med. Assoc. 2020, 323, 1061.

[10] Phelan, A.; Katz, R.; Gostin, L. The novel coronavirus originating in Wuhan, China. JAMA- J. Am. Med. Assoc. 2020, 323, 709 .

[11] Aladakatti, R.; Ghodesawar, M.; Ahmed, M.; Totiger, T.; Sannadurgappa, D. Effect of lyophilized Azadirachta indica leaf powder on biochemical parameters of testis and epididymis in albino rats. Int. J. Biol. Chem. Sci. 2010, 4, 75-87.

[12] Lee, J.; Ryu, H.; Park, S.; Park, H.; Kwon, O.; Yuk, H.; Shrestha, K.; Park, M.; Kim, J.; Lee, S.; Oh, S.; Ahn, K. Protective effects of neem (Azadirachta indica A. Juss.) leaf extract against cigarette smoke- and lipopolysaccharide-induced pulmonary inflammation. Int. J. Mol. Med. 2017, 1932-1940.

[13] Tiwari, V.; Darmani, N.; Yue, B.; Shukla, D. In vitro antiviral activity of neem (Azardirachta indica L.) bark extract against herpes simplex virus type-1 infection. Phytother. Res. 2009, 24, 1132-1140.

[14] Srivastava, S.; Agrawal, B.; Kumar, A.; Pandey, A. Phytochemicals of AzadirachtaIndica source of active medicinal constituent used for cure of various diseases: A Review. J. Sci. Res. 2020, 64, 285-290.

[15] Alzohairy, M. Therapeutics role of Azadirachta indica (Neem) and their active constituents in diseases prevention and treatment. Evid-Based Compl. Altern. Med. 2016, 12, 1-11.

[16] Juteau, F.; Masotti, V.; Bessière, J.; Dherbomez, M.; Viano, J. Antibacterial and antioxidant activities of Artemisia annua essential oil. Fitoterapia 2002, 73, 532-535.

[17] De Logu, A.; Loy, G.; Pellerano, M.; Bonsignore, L.; Schivo, M. Inactivation of HSV-1 and HSV-2 and prevention of cell-to-cell virus spread by Santolina insularis essential oil. Antivir. Res. 2000, 48, 177-185.

[18] Chen, W.; Vermaak, I.; Viljoen, A. Camphor-A fumigant during the black death and a coveted fragrant wood in ancient egypt and babylon-A review. Molecules. 2013, 18, 5434-5454.

[19] Song, J.; Lee, K.; Seong, B. Antiviral effect of catechins in green tea on influenza virus. Antivir. Res.2005, 68, 66-74.

[20] Nakane, H.; Ono, K. Differential inhibitory effects of some catechin derivatives on the activities of human immunodeficiency virus reverse transcriptase and cellular deoxyribonucleic and ribonucleic acid polymerases. Biochemistry 1990, 29, 2841-2845.

[21] Furushima, D.; Nishimura, T.; Takuma, N.; Iketani, R.; Mizuno, T.; Matsui, Y.; Yamaguchi, T.; Nakashima, Y.; Yamamoto, S.; Hibi, M.; Yamada, H. Prevention of acute upper respiratory infections by consumption of catechins in healthcare workers: A randomized, placebo-controlled trial. Nutrients 2019, 12, 1-12. 
[22] Ferreira, P.; Ferraz, A.; Figueiredo, J.; Lima, C.; Rodrigues, V.; Taranto, A.; Ferreira, J.; Brandao, G.; VieiraFilho, S.; Duarte, L.; de Brito Magalhaes, C.; de Magalhaes, J. Detection of the antiviral activity of epicatechin isolated from Salacia crassifolia (Celastraceae) against mayaro virus based on protein $\mathrm{C}$ homology modelling and virtual screening. Arch. Vir. 2018, 163, 1567-1576.

[23] Warowicka, A.; Nawrot, R.; Goździcka-Józefiak, A. Antiviral activity of berberine. Arch. Vir. 2020, 165, 1935-1945.

[24] Zou, K.; Li, Z.; Zhang, Y.; Zhang, H.; Li, B.; Zhu, W.; Shi, J.; Jia, Q.; Li, Y. Advances in the study of berberine and its derivatives: a focus on anti-inflammatory and anti-tumor effects in the digestive system. Acta Pharm. Sinica. 2016, 38, 157-167.

[25] Tew, X.; Xin Lau, N.; Chellappan, D.; Madheswaran, T.; Zeeshan, F.; Tambuwala, M.; Aljabali, A.; Balusamy, S.; Perumalsamy, H.; Gupta, G.; Oliver, B.; Hsu, A.; Wark, P.; Reddy, K.; Wadhwa, R.; Hansbro, P.; Dua, K. Immunological axis of berberine in managing inflammation underlying chronic respiratory inflammatory diseases. Chem. Biol. Interact. 2020, 317, 108947.

[26] Wu, Y.; Li, J.; Kim, Y.; Wu, J.; Wang, Q.; Hao, Y. In vivo and in vitro antiviral effects of berberine on influenza virus. Chin. J. Integr. Med. 2011, 17, 444-452.

[27] Jadhav, V. Anti- SARS-COV-2 main protease complex (mpro) activity of palmatine. Res. square. 2020, 1-19.

[28] Ho, Y.; Lu, J.; Huang, Y.; Lai, Z. Palmatine Inhibits Zika Virus infection by disrupting virus binding, entry, and stability. Biochem. Biophys. Res. Commun. 2019, 518, 732-738.

[29] Jia, F.; Zou, G.; Fan, J.; Yuan, Z. Identification of palmatine as an inhibitor of west nile virus. Arch. Vir. 2010, 155, 1325-1329.

[30] Borgaonkar, M.; Townson, G.; Donnelly, M.; Irvine, E. Providing disease-related information worsens healthrelated quality of life in inflammatory bowel disease. Inflamm. Bowel Dis. 2002, 8, 264-269.

[31] Leyva-López, N.; Gutierrez-Grijalva, E.; Ambriz-Perez, D.; Heredia, J. Flavonoids as cytokine modulators: a possible therapy for inflammation-related diseases. Int. J. Mol. Sci. 2016, 17, 921-936.

[32] Bahri, S.; Mies, F.; Ben Ali, R.; Mlika, M.; Jameleddine, S.; Mc Entee, K.; Shlyonsky, V. Rosmarinic acid potentiates carnosic acid induced apoptosis in lung fibroblasts. PLOS ONE. 2017, 12, e0184368.

[33] Costa, R.S.; Carneiro, T.C.; Cerqueira-Lima, A.T.; Queiroz, N.V.; Alcântara-Neves, N.M.; Pontes-deCarvalho, L.C.; da Silva Velozo, E.; Oliveira, E.J.; Figueiredo, C.A. Ocimumgratissimum Linn. and rosmarinic acid, attenuate eosinophilic airway inflammation in an experimental model of respiratory allergy to Blomia tropicalis. Int. Immunopharmacol. 2012, 13, 126-134.

[34] Lin, W.; Yu, Y.; Jinn, T. Evaluation of the virucidal effects of rosmarinic acid against enterovirus 71 infection via in vitro and in vivo study. Virol. J. 2019, 16, 94-103.

[35] Swarup, V.; Ghosh, J.; Ghosh, S.; Saxena, A.; Basu, A. Antiviral and anti-Inflammatory effects of rosmarinic acid in an experimental murine model of Japanese encephalitis. Antimicrob. Agents Chemother. 2007, 51, 3367-3370.

[36] Patel, A.; Malathi, R.; Shah, A.; Patel, H.; Pakala, S.B.; Karyala, P. Virtual screening of curcumin and its analogs against the spike surface glycoprotein of SARS-CoV-2 and SARS-CoV. J. Biomol. Struct. Dyn. 2021, $1-11$.

[37] Morris, G.; Huey, R.; Lindstrom, W.; Sanner, M.; Belew, R.; Goodsell, D.; Olson, A. Autodock4 and Autodocktools4: Automated docking with selective receptor flexibility. J. Comput. Chem. 2009, 30, 27852791.

[38] Gasteiger, J.; Marsili, M. Iterative partial equalization of orbital electronegativity-a rapid access to atomic charges. Tetrahedron 1980, 36, 3219-3228.

[39] Morris, G.; Goodsell, D.; Halliday, R.; Huey, R.; Hart, W.; Belew, R.; Olson, A. Automated docking using a lamarckian genetic algorithm and an empirical binding free energy function. J. Comput. Chem. 1998, 19, 16391662.

[40] Pires, D.; Blundell, T.; Ascher, D. Pkcsm: Predicting small-molecule pharmacokinetic and toxicity properties using graph-based signatures. J. Med. Chem. 2015, 58, 4066-4072.

[41] Kumar, A.; Choudhir, G.; Shukla, S.K.; Sharma, M.; Tyagi, P.; Bhushan, A.; Rathore, M. Identification of phytochemical inhibitors against main protease of COVID-19 using molecular modeling approaches. $J$. Biomol. Struct. Dyn. 2020, 1-11.

[42] Narkhede, R.; Pise, A.; Cheke, R.; Shinde, S. Recognition of natural products as potential inhibitors of COVID19 main protease (Mpro): In-silico evidence. Natural products and Bioprospecting, 2020, 10, 297-306.

[43] Das, P.; Majumder, R.; Mandal, M.; Basak, P. In-Silico approach for identification of effective and stable inhibitors for COVID-19 main protease (Mpro) from flavonoid based phytochemical constituents of Calendula officinalis. J. Biomol. Struct. Dyn. 2020, 1-16.

[44] Khaerunnisa, S.; Kurniawan, H.; Awaluddin, R.; Suhartati, S.; Soetjipto, S. Potential inhibitor of COVID-19 main protease (Mpro) from several medicinal plant compounds by molecular docking study. Preprints 2020 , $1-14$. 
Exploring the potential of natural compounds as a SARS-CoV-2 protease inhibitors

[45] Mishra, A.; Pathak, Y.; Choudhir, G.; Kumar, A.; Mishra, S.K.; Tripathi, V. Natural compounds as potential inhibitors of novel coronavirus (COVID-19) main protease: An in silico study. Preprints 2020, 1-14.

[46] Adem, S.; Eyupoglu, V.; Sarfraz, I.; Rasul, A.; Ali, M. Identification of potent COVID-19 main protease (Mpro) inhibitors from natural polyphenols: an in silico strategy unveils a hope against CORONA. Preprints 2020, 1-17.

[47] Nugraha, R.; Ridwansyah, H.; Ghozali, M.; Khairani, A.; Atik, N. Traditional herbal medicine candidates as complementary treatments for COVID-19: A review of their mechanisms, pros and cons. Evidence-Based Compl. Alt. Med. 2020, 2020, 1-12.

[48] Burger, R.; Torres, A.; Warren, R.; Caldwell, V.; Hughes, B. Echinacea-induced cytokine production by human macrophages. Int. J. Immunopharmacol. 1997, 19, 371-379.

[49] Das, S.; Sarmah, S.; Lyndem, S.; Singha Roy, A. An investigation into the identification of potential inhibitors of SARS-CoV-2 main protease using molecular docking study. J. Biomol. Struct. Dyn. 2020, 1-11.

[50] Li, H.; Yang, M.; Li, Z.; Meng, Z. Curcumin inhibits angiotensin II-induced inflammation and proliferation of rat vascular smooth muscle cells by elevating PPAR- $\gamma$ activity and reducing oxidative stress. Int. J. Mol. Med. 2017, 39, 1307-1316.

[51] Manoharan, Y.; Haridas, V.; Vasanthakumar, K.; Muthu, S.; Thavoorullah, F.; Shetty, P. Curcumin: a wonder drug as a preventive measure for COVID19 management Ind. J. Clin. Biochem. 2020, 35, 373-375.

[52] Michelini, F.; Alché, L.; Bueno, C. Virucidal, antiviral and immunomodulatory activities of $\beta$-escin and aesculus hippocastanum extract. J. Pharm. Pharmacol. 2018, 70, 1561-1571.

[53] Yang, Y.; Wang, L.; Yuan, M.; Yu, Q.; Fu, F. Anti-Inflammatory and gastroprotective effects of escin. Nat. Prod. Commun. 2020, 15, 1-10.

[54] Shah, A.; Patel, V.; Parmar, B. Discovery of some antiviral natural products to fight against novel corona virus (SARS-CoV-2) using insilico approach. Comb. Chem. High Throughput Screen. 2020, 1-12.

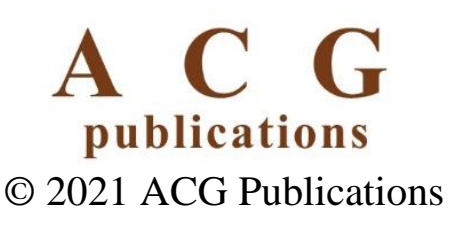

